\title{
Looking beyond the obvious to figure out the Entry Points of Racial Awareness and Bias in Children: A Commentary of Waxman (2021)
}

\author{
Shardul Shankar \\ Department of Management Studies, Indian Institute of Information Technology, Allahabad, India \\ Email: shane.shardul@gmail.com
}

In "Racial Awareness and Bias Begin Early: Developmental Entry Points, Challenges, and a Call to Action", Waxman (2021) argues that there is a dramatic overestimation by the community when it comes to evidence of the time-frame when it should be discussed with children (p. 898). To counter this problem, they promote the intention of identifying "the developmental roots of these prejudices, forces that sustain them, and pathways to reduce them" (p. 893). The goal of Waxman is to advance the entry points of this bias, especially in our infants and children, as there are obvious and apparent damaging consequences to the children, their communities and the society as a whole. They advocate the use of a more "comprehensive research agenda", specifically the use of larger empirical base, methodological tool-kit, and psychological-science framework to identify the preliminary stages of the acquisition of racial bias. They look back into the large body of experimental and empirical evidence to provide an overview of the development of racial bias in young children and infants. They then provide a substantially comprehensive framework to tackle this issue. Finally, Waxman argues that the strongest tool to advance the understanding and tackling of early racial bias is by arming the parents, teachers, and other policymakers with strong empirical evidence and evidence-based recommendations, which would allow for better conversations within the families and classrooms.

Waxman (2021) argues that the children are exposed to racial bias from their communities; neighborhoods, homes and classrooms. They not only discuss about the individual race bias, but also about the racism as an institutional issue. This study draws on a large body of research and few experimental studies indicating that racial prejudices and biases present themselves in young children, even as young as 3-months old (Bar-Haim et al., 2006). This study is extremely timely and does the academia a great service, by analyzing the factors of early racial biases, and what methods can be used to interrupt and eventually eliminate the effects of race. I agree with Waxman's arguments, but I would like to present the argument that discussing about only the communities of children, especially pre-school and K-12 students, as the only variables of developmental entry points to this bias, might not be enough. Also, one should be vary of putting the burden of developmental entry points to experiences of racial expressions to white people only. 
As the nation, and subsequently the whole of western world were rocked by the brutal murder of George Floyd, the US was highly politically charged and divided for the next year. For a parent, it was an impossible task, teaching their kids what was happening. The elements that were fueling this divide, which I believe are essential elements that were missed in this study, was the traditional media, social media, and entertainment industry's response to it all. I believe that in discussions of early racial bias, one should not undermine the role that these three media outlets play in reinforcing the racial expressions.

If a person flicks through the news outlets, you could hear that there is altogether a different country that is being discussed in those reporting (Titley, 2019). No more it was apparent when there were discussions about Breonna Taylor, Jacob Blake, George Floyd, David Dorn, etc. Then there are anti-Asian crimes, invasion of US Capitol, protests of Floyd's murder. If you were to look for these four names through your preferred news outlets and other outlets, you would find enormous discrepancies in the information about each case.

When talking about children forming racial categories, the author acknowledges the role of direct experiences, as well as beliefs and societal expectations transmitted (p. 894) on them, as presented by psychological essentialism, or cognitive bias. However, the author misses the role that the western media plays in formation of these biases, stereotypes and "hidden properties" (p. 895).

There's also the social media giants' continued resistance to fix their broken websites and apps, along with their continued insistence on the fact that their platforms are transparent (Lamson, 2021). Any parent or person looking to understand how microaggressions work could be safely pointed towards any of the social media platforms as evidence.

A September article in Wall Street Journal (Wells et al., 2021) showed that Facebook has conducted a series of in-depth studies regarding the negative mental health issues associated with Instagram, especially to young children, and has severely and publicly downplayed its adverse effects. Since then, there have been accusations aplenty by the whistleblower, on the show "60 minutes" and other subsequent interviews (Scott, 2021). Saying that the platforms have significant influence on the racial intolerance in US would be an understatement, and must be accounted for when talking about the racial entry points.

As adults, it is easy to see that the under-representation of racial diversity in the entertainment industry reflects the prejudices of society, but as a child, it is especially harmful. Numerous studies have shown that racial representation in movies, TVs and other media outlets have overall positive impacts on people of color (Keating, 2021; Benziane and Abdelhay, 2020; Borum Chattoo, 2018; Gonzalez-Sobrino et al., 
2018; Burgin, 2018). Unfortunately, the industry has a shady past, at best, when it pertains to racial diversity (Washington, 2019; Burgin, 2018).

Why could these factors be important in understanding the learnings of racial bias in children? Well, as Pashtana Usufzy (2020) states, "It's in the details left out and the victims who never had their stories told." A great example would be the shootings of Jacob Blake and David Dorn. While the nation was grieving George Floyd's death, all the three media bodies unfairly glorified the crimes of Jacob Blake over the victim (black woman of color and her children), and completely ignored the fatal shooting of retired Officer Dorn. A similar coverage was to the incident of Breonna Taylor, where the media was clearly politically inclined and charged to incriminate an already dead woman of color. There are too many cases similar to these in the media, social media, or entertainment industry to ignore the adverse psychological impact it has on young, impressionable children. These omitted reporting of facts makes it difficult for people to get complete information, and this, in turn, creates a circle of reinforcement of racial stereotypes.

When impressionable young children are exposed to, and/or have conversations with their parents and educators about such incidents, these incomplete information and coverage create a loop of stereotypes and/or projections, which result in promotion of further racial divide. It is as Waxman said, "Children are keen observers, taking in not only what they hear but also what they see. ...both verbal and non-verbal behaviors serve as powerful source of bias." (p. 895).

In the section of definition of race and racism, Waxman introduces the idea of "Whiteness", and "white people" (p. 894), which must be terminologically differentiated. They rightly talk about the privilege that white people experience, but they use "white people" and "whiteness" interchangeably throughout the article, which sets a dangerous precedent. It assumes that there is no intellectual and behavioral diversity amongst people of white race. This study also excludes any kind of intersectional examination. One should be vary of generalizations based on race, especially "white racelessness", when talking to or about children. This is important to see because young children, especially 5 year-olds or lesser, develop the cognitive capability to remember things that are heard, read or seen repeatedly by them, and exposing children, both white children and children of color, with only the negative stereotypes would only be spreading negative stereotypes. Talking about racial hierarchy is important, but putting the onus of all the perils of racial issues on the shoulders of very young kids, of any race, would be unfair and counterproductive. They are at the age where they are beginning to learn about their society, and the stakeholders must be proactive in teaching them about the racial gap, not putting them in a box. 
It is pretty clear from evidences in research that racial recognition occurs early to infants. There is also a similar underlying pathway between the racial bias and gender bias. But as the example quoted by Waxman, the Bar-Haim (2006) study showed that infants that were living in a racially diverse community, showed little to no preference to faces of different race. Similar findings were obtained by other researchers (Meissner and Brigham, 2001; MacLin and Malpass, 2001; Bar-haim, Saidel and Yovel, 2009; Otsuka, 2013). In fact, Bar-haim's (2009) future study concluded that “...despite the notion that skin colour plays a major role in categorising faces into own and other-race faces, its effect on face recognition is minor relative to differences across races in facial features. In fact, other-race facial features appear to serve as a primary racial marker that reduces face recognition. And, only once a face is categorised as belonging to one's own race on the basis of its features, colour becomes an additional component that modulates recognition."

This is important to understand because if we want to fix the racial intolerance correctly, we must realize that inclusion is a necessary part in overcoming it. This is also a major flaw of the huge landmark "doll test" (Clark and Clark, 1950). The study, even though, provided a pointed understanding of racial segregation in the US, and was instrumental in the monumental decision to end school segregations (see Brown v Board of Education, 1954), it was not free from its scientific flaws. Some of them include (a) Not covering the racially un-segregated schools of US (which are now almost every school), and (b) completely excluding any other racial minority. It is imperative that the "doll test" is updated according to the changing times, as it could provide some crucial understandings of racial inequities in the US, especially in this present diverse, non-segregated school times.

Bernstein's (2011) findings explain that preference of white dolls over black dolls by children, especially of African-American descent, can be pointed towards cultural choice for loving one and hating the other, which is a result of not only black hatred, but also black self-hatred. This can clearly be seen on our popular media (Bernstein, 2017), including social media.

An important point that was brought up by Waxman, but not explored in detail, was the discussions about positive expressions of race. When people are talking to their kids about their race and the societal expectations, one must always talk about the positive elements of race. Researches like Bachman et al. (2010; 2011), Hoff (2020) and Rushton and Jensen (2005) discuss about multiple positive racial differences in various races that must be used when talking about race with children.

I think the section that talks about the hesitance that is present in the white community in regards to race conversation must be talked about more. It is well documented that a majority of white people (and 
people of other races too) avoid these discussions, especially with their children. But it must not only be attributed to the fact that parents overestimate the age for these discussions. A more holistic view would be why white people are scared of talking about it at all? Articles like McIntosh (2009) focus on these topics. Some of the common reasons include: (a) Exclusion of white people from the discussions of racism, (b) Blaming of sins of everyone on that one white person in the discussion, (c) White racelessness portrayal by popular media, amongst others. If we want to fix the racial intolerance and injustice in United States, white people must be included in this discussion, or we're basically becoming the same demon we vowed to fight against.

There is an important misconception when it comes to talking about the societal structure that would help the US; the conflict between the "color-conscious" approach and "color-blind" approach. Waxman writes that one should “...leave behind the color-blind approach" (p. 898), but you can be a color-conscious society without forgoing the ideal of a color-blind society. These are not mutually exclusive; instead, one should use the color-conscious approach as a catalyst to attain a color-blind society. Then only would we obtain a truly racially equal society. A society should be striving towards being color-blind, by fighting it's demons through the color-conscious approach.

A great example is covered by Waxman herself, when they discussed about the Bar-haim et al. (2006) findings, which showed that families living in a majorly diverse community had a more color-blind response from the infants. In the future study by Bar-haim (2008), he elaborated on this point by saying that newborns have an innate face recognition mechanism, and this preference for specific configurations disappear within months of birth, and skin color becomes an additional component that modulates recognition, once the infant starts recognizing the differences in the other facial features.

To conclude, I think that a full-fledged crusade to microaggressions and developmental early points of racial bias injection in a child's life must not merely be a matter of employing more "methodologically valid" and "empirically strong" framework and settings. The problem of this avenue is that we do not have all the factors in-front of us. What we all have is driven by anecdotal experiences, ideas (sometimes misguided and politically motivated), confused hypotheses, and the obvious perpetrators (who are at times, ignorant, or innocent). One should be looking for the "hidden" elements, not only "hidden" properties, to racial bias. Also, one should not only be worried about "when" to start the discussions of race and its biases, but should be more worried, and essentially, more focused on "how" to start this conversation. As Waxman suggests, arming the general populous with the right tools to adequately evaluate, assess and critically discuss the relevant aspects of a scenario, in its individual stature would be 
the strongest way to bridge this racial divide, without harming the childhood of a child, or the children around it. As Gilliam et al. (2016) explains,

Biases... form naturally through the course of everyday interactions and exposure to media. ...everyone may benefit from increased training and ongoing guidance, ... to understand the use of this information, increase the empathic understanding of the child, and avoid feelings of hopelessness, especially when race of child and educator does not match (2016, p. 15).

\section{References}

Waxman, S. R. (2021). Racial Awareness and Bias Begin Early: Developmental Entry Points, Challenges, and a Call to Action. Perspectives on Psychological Science, 16(5), 893-902. https://doi.org/10.1177/17456916211026968

Bar-Haim, Y., Ziv, T., Lamy, D., \& Hodes, R. M. (2006). Nature and Nurture in Own-Race Face Processing. Psychological Science, 17(2), 159-163. https://doi.org/10.1111/j.14679280.2006.01679.x

Titley, G. (2019). Racism and Media (1st ed.). SAGE Publications Ltd.

Lamson, M. (2021, January 5). Being Transparent on Facebook is a Leader's Key to Success. Inc.Com. https://www.inc.com/melissa-lamson/mark-zuckerberg-is-making-leadership-transparency-hotright-now.html

Wells, G., Horwitz, J., \& Seetharaman, D. (2021, September 14). Facebook Knows Instagram Is Toxic for Teen Girls, Company Documents Show. WSJ. https://www.wsj.com/articles/facebook-knowsinstagram-is-toxic-for-teen-girls-company-documents-show-11631620739

Scott, S. (2021, October 5). Facebook whistleblower Frances Haugen details company's misleading efforts on 60 Minutes. CBS News. https://www.cbsnews.com/news/facebook-whistleblowerfrances-haugen-misinformation-public-60-minutes-2021-10-03/

Keating, K. (2021). The Economic Impact of Racism in the Entertainment Industry. DigitalCommons@SHU. https://digitalcommons.sacredheart.edu/acadfest/2021/all/1/ 
Benziane, M. N., \& Abdelhay, B. (2020). Arab Muslims In TV Screens:, The Reproduction Of Reality By مجلة . The American Entertainment Industry In The Age Of Contemporary Radical Armed Groups آفاق علمية, 21. https://doi.org/10.35554/1697-012-002-041

Borum Chattoo, C. (2018). Oscars So White: Gender, Racial, and Ethnic Diversity and Social Issues in U.S. Documentary Films (2008-2017). Mass Communication and Society, 21(3), 368-394. https://doi.org/10.1080/15205436.2017.1409356

Gonzalez-Sobrino, B., Hughey, M. W., \& González-Lesser, E. (2018). On-demand diversity? the meanings of racial diversity in Netflix Productions. Challenging the Status Quo, 321-344. https://doi.org/10.1163/9789004291225_017

Burgin, Xavier. Personal Interview. February $24^{\text {th }}, 2018$.

Washington, L. (2019, December 30). The Importance of Representation in Film and Media - Lauren Washington. Medium. https://medium.com/@Laurenwash/the-importance-of-representation-infilm-and-media-2d006149cac9

Usufzy, P. (2020). Unpacking How Media Influences Our Views on Racism. University of Nevada, Las Vegas. https://www.unlv.edu/news/article/unpacking-how-media-influences-our-views-racism

Meissner, C. A., \& Brigham, J. C. (2001). Thirty years of investigating the own-race bias in memory for faces: A meta-analytic review. Psychology, Public Policy, and Law, 7(1), 3-35. https://doi.org/10.1037/1076-8971.7.1.3

MacLin, O. H., \& Malpass, R. S. (2001). Racial categorization of faces: The ambiguous race face effect. Psychology, Public Policy, and Law, 7(1), 98-118. https://doi.org/10.1037/1076-8971.7.1.98

Bar-Haim, Y., Saidel, T., \& Yovel, G. (2009). The Role of Skin Colour in Face Recognition. Perception, 38(1), 145-148. https://doi.org/10.1068/p6307

Otsuka, Y. (2013). Face recognition in infants: A review of behavioral and near-infrared spectroscopic studies. Japanese Psychological Research, 56(1), 76-90. https://doi.org/10.1111/jpr.12024

Clark, K. B., \& Clark, M. P. (1950). Emotional Factors in Racial Identification and Preference in Negro Children. The Journal of Negro Education, 19(3), 341. https://doi.org/10.2307/2966491 
Warren, E. \& Supreme Court Of The United States. (1953) U.S. Reports: Brown v. Board of Education, 347 U.S. 483. [Periodical] Retrieved from the Library of Congress, https://www.loc.gov/item/usrep347483/.

Bernstein, R. (2011). Racial Innocence: Performing American Childhood from Slavery to Civil Rights. New York, USA: New York University Press. https://doi.org/10.18574/9780814787090

Bernstein, R. (2017, July 26). Opinion | Let Black Kids Just Be Kids. The New York Times. https://www.nytimes.com/2017/07/26/opinion/black-kids-discrimination.html

Bachman, J. G., O’Malley, P. M., Johnston, L. D., Schulenberg, J. E., \& Wallace, J. M. (2011). Racial/Ethnic Differences in the Relationship Between Parental Education and Substance Use Among U.S. 8th-, 10th-, and 12th-Grade Students: Findings From the Monitoring the Future Project. Journal of Studies on Alcohol and Drugs, 72(2), 279-285. https://doi.org/10.15288/jsad.2011.72.279

Bachman, J. G., O’Malley, P. M., Freedman-Doan, P., Trzesniewski, K. H., \& Donnellan, M. B. (2010). Adolescent Self-esteem: Differences by Race/Ethnicity, Gender, and Age. Self and Identity, 10(4), 445-473. https://doi.org/10.1080/15298861003794538

Hoff, E. (2020). Lessons from the study of input effects on bilingual development. International Journal of Bilingualism, 24(1), 82-88. https://doi.org/10.1177/1367006918768370

Rushton, J. P., \& Jensen, A. R. (2005). Thirty years of research on race differences in cognitive ability. Psychology, Public Policy, and Law, 11(2), 235-294. https://doi.org/10.1037/1076-8971.11.2.235

McIntosh, P. (2009). White People Facing Race: Uncovering the Myths that Keep Racism in Pla. [online] Taylor \& Francis. Available at: <https://www.taylorfrancis.com/chapters/mono/10.4324/9781351133791-8/white-people-facingrace-uncovering-myths-keep-racism-place-2009-1-peggy-mcintosh> [Accessed 6 October 2021].

Gilliam, W. S., Maupin, A. N., Reyes, C. R., Accavitti, M., \& Shic, F. (2016). Do early educators' implicit biases regarding sex and race relate to behavior expectations and recommendations of preschool expulsions and suspensions. Yale University Child Study Center, 9(28), 1-16. 